\title{
Discovering the Mathematical Formula of The Universal Law of Harmony of the CREATOR and the Law of Harmony of GOD to Ensure a Holistic Sustainable Development of Man and Humanity
}

\author{
Nikolay Suvorov ${ }^{1}$ and Irina Suvorova ${ }^{2}$
}

\begin{abstract}
A mathematical formula was obtained to express the universal Law of Harmony of the CREATOR and the Law of Harmony of GOD, the formula being determined by the condition of orthogonality - orthonormality.

New methods were created for development of the Man of the future, based on modern mathematical proofs of the objective truth.

Orthogonality is shown to be at the heart of energy-information systems.

Orthogonality is the key principle of selection and mutual differentiation of a variety of energyinformation images, structures and systems.

Orthogonality defines the quality and effectiveness of functioning of energy-information systems.

Orthogonality defines the principles of building modern and prospective energy-information systems.

Orthogonality and orthonormality is the path to a constructive energy-information mathematical science.

Using isomorphism, one can synthesise not only optimal engineering but also perfect bioenergyinformation systems. The problem of development of a perfect Man can be solved after the perfection criterion has been substantiated. Substantiating and establishing the criteria of Man's perfection makes solving the problem of developing a perfect Man real.

Man who is perfect according to the criteria of maximum harmony is a holistic orthogonally orthonormalised image having supreme moral and ethical qualities, and the energy of PEACE and LOVE.
\end{abstract}

Keywords: holistic sustainable development, Law of Harmony of the CREATOR, Law of Harmony of GOD.

In every department of physical science there is only

so much science, properly so-called,

as there is mathematics

Immanuel Kant

\section{Introduction}

The discovery of the mathematical formula of the universal Law of Harmony of the CREATOR and the Law of Harmony of GOD is the discovery of new methods for development of the Man of the future, which are based on modern mathematical proofs of the objective truth.

| 1Dr, Prof, Research Division, Private Company, Kharkov, Ukraine.

${ }^{2}$ Dr, Prof, The A.N. Podgorny Institute for Mechanical Engineering Problems (IPMach) of The National Academy of Sciences of Ukraine (NAS of Ukraine), Kharkov, Ukraine. 


\section{Definition}

Two functions $\varphi(\mathrm{x})$ and $\psi(\mathrm{x})$, determined on interval $[\mathrm{a}, \mathrm{b}]$ are called orthogonal if the conditions [1] are satisfied:

$$
\begin{gathered}
\int_{\mathrm{a}}^{\mathrm{b}} \varphi(\mathrm{x}) \psi(\mathrm{x}) \mathrm{dx}=0, \\
\int_{\mathrm{a}}^{\mathrm{b}} \varphi^{2}(\mathrm{x}) \mathrm{dx}=\int_{\mathrm{a}}^{\mathrm{b}} \psi^{2}(\mathrm{x}) \mathrm{dx}=\lambda>0 .
\end{gathered}
$$

Subject to $\lambda=1$, orthogonal functions change to the class of orthonormal ones. Any orthogonal functions become orthonormal ones by introducing the factor $\varphi(x) / \sqrt{\lambda}$ [1]. Orthogonality-orthonormality jointly is defined also by the mutual correlation coefficient $r$ equal to " $0 "$ - zero $(r=0)$

$$
\mathrm{r}=\int_{\mathrm{a}}^{\mathrm{b}} \varphi(\mathrm{x}) \psi(\mathrm{x}) \mathrm{dx}=0,
$$

and autocorrelation coefficient $\rho$, equal to "1" - unit $(\rho=1)$

$$
\rho=\int_{\mathrm{a}}^{\mathrm{b}} \varphi(\mathrm{x}) \varphi(\mathrm{x}) \mathrm{dx}=\int_{\mathrm{a}}^{\mathrm{b}} \psi(\mathrm{x}) \psi(\mathrm{x}) \mathrm{dx}=\int_{\mathrm{a}}^{\mathrm{b}} \varphi^{2}(\mathrm{x}) \mathrm{dx}=\int_{\mathrm{a}}^{\mathrm{b}} \psi^{2}(\mathrm{x}) \mathrm{dx}=1 .
$$

The notions of orthogonality, orthonormality, mutual correlation, and autocorrelation help mathematics give a clear and precise definition of harmony, form LOGOS HARMONY, and unveil the meaning of the universal Law of Harmony of the CREATOR and the Law of Harmony of GOD [2 - 7].

LOGOS HARMONY - a word (a multitude of words) and mathematical formulas united by reason into a whole.

\section{General definition of harmony}

The Explanatory Dictionary of the Russian Language by V. Dahl [8] defines harmony as follows: harmony - correspondence, consonance, commensuration, equilibrium, equal soundness, eurhythmy, concinnity of proportion of parts of a whole, proper relation of consonant sounds, accords, science of consonance.

Modern encyclopaedic dictionaries define harmony as orderliness, commensuration, correspondence, coherence.

Harmony is a Greek word. It has many semantic meanings and facets to it. The most important of these are as follows:

- $\eta \alpha \rho \mu o v i \alpha$ (h armonia) - orderliness, consonance, coherence, and agreement;

- $\eta \varepsilon v \varphi \omega v i \alpha$ (h euphonia) - euphony;

- $\quad \eta \sigma v \mu \varphi \omega$ (h simphonia) - concord, coherence, affinity, correspondence, agreement, contract. 
The facets of harmony - armonia, euphony, and symphony are inseparably linked to music, poetry, art and architecture, as a whole, with art and beauty.

The most significant facets of harmony are in the words: agreement, covenant, arrangement, contract, convention, and affinity.

A special meaning for understanding the content of harmony is imparted by Greek words defining ethics, in particular, like-mindedness $(\eta$ o $\mu \boldsymbol{\nu} \boldsymbol{\imath} \boldsymbol{\alpha}-\mathrm{h}$ omonia) and consentience ( $\eta$ o

\section{The mathematical treatment of harmony}

Presently, not only have the fundamentals of the theory of harmony been formulated, but even primary knowledge of the term harmony has not been outlined yet. At this point, one can speak only about certain primary principles of harmony and basic tenets of harmony, including the analysis of the term harmony.

The mathematical theory of functional analysis, as well as the theory of simple and complex signals of information systems help reverse the situation cardinally. A special and crucial role belongs to the spectral-correlation theory based on such notions as harmonic, harmonic function, harmonic series.

The words harmonic, harmonical, harmonious and similar ones have one root with the word harmony.

They are united into a whole by orthogonality, orthogonal functions, and the orthogonal basis. The property of orthogonality is a wonderful gift of the Supreme Mind for the intense development of different energy-information systems.

The basis of orthogonal functions is used in multichannel energy-information systems as an information carrier.

Orthogonality excludes mutual noise among different energy-information objects to ensure high-quality information transmission and receipt.

The orthogonality of information carriers facilitated the origination of digital methods of transmission of analog telephone and television messages, and cellular local and global communication.

All the informatics in Shannon's sense came to being due to orthogonality [9].

The property of orthogonality is at the heart of energy-information systems.

Orthogonality is the key principle of selection and mutual separation of a variety of energy-information images, structures and systems.

Orthogonality defines the quality and effectiveness of functioning of energy-information systems.

Orthogonality defines the principles of building modern and prospective energyinformation systems.

Orthogonality and orthonormality is the path to a constructive energy-information mathematical science.

\section{The correlation method of defining harmony}

The meaning of the word "harmony" is disclosed principally by the term "correlation" and its derivatives - autocorrelation and mutual correlation. 
Correlation - coordination, coherence, accord, affinity, correspondence, balance, fusion, coincidence, similarity, equality.

Autocorrelation - coherence, coincidence, similarity, agreement, affinity, fusion with a paragon or ideal image.

Mutual correlation - balance, equilibrium, equability of opposites, opposite categories, and opposite energies.

Auto and mutual correlation have a mathematical definition, hence, harmony can be defined mathematically. To this end, the mathematical expressions for the coefficients of autocorrelation and mutual correlation have to be analysed.

When analysing engineering energy-information systems, certain words corresponding to

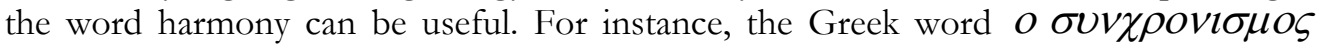
(synhronismos) can be related to such associated words as synchronicity, simultaneity, and synchronism.

Another interesting related word is resonance. In Greek, resonance is $\eta \alpha v \tau \eta \chi \eta \sigma \eta$ (antihisi). The word antihisi also means echo. Resonance, from the engineering standpoint, implies complete affinity, coincidence, for instance, of two energyinformation images, in particular, the equality of the radiating frequency of the transmitting station and the tuning frequency of the resonance circuit of the receiving station. Here, note that resonance can be not only a single-parameter one (by frequency), but a multiparametric one as well - by frequency, phase, time delay, and an integral (full) form of energy-information images.

Resonance-echo is a fine addition to understanding such facets of harmony as coherence, coincidence, similarity, and resemblance to a paragon or ideal image.

In classical mathematics, the autocorrelation function, or correlation $\mathrm{R}(\tau)$ ), is written as

$$
\mathrm{R}(\tau)=\int_{\{\mathrm{t}\}} \mathrm{f}(\mathrm{t}) \mathrm{f}(\mathrm{t}-\tau) \mathrm{dt},
$$

where $f(t)$ is an arbitrary deterministic function;

$\mathrm{f}(\mathrm{t}-\tau)$ is a function with a time shift of $\tau$ with respect to $\mathrm{t}$;

$\{t\}$ is domain of definition of parameter $t$, which can be a finite or infinite quantity.

The mutual correlation function, or mutual correlation $\mathrm{B}_{\mathrm{xy}}(\tau)$, has the form

$$
\mathrm{B}_{\mathrm{xy}}(\tau)=\int_{\{\mathrm{t}\}} \mathrm{x}(\mathrm{t}) \mathrm{y}(\mathrm{t}-\tau) \mathrm{dt},
$$

where $\mathrm{x}(\mathrm{t})$ and $\mathrm{y}(\mathrm{t}-\tau)$ are arbitrary functions with time shift $\tau$ between them.

The correlation method of research established that, mathematically, the interpretation of the harmony of simple and complex engineering, anthropological, and biological images and systems is unified.

Mathematically, harmony is the universal generalised criterion of the quality of internal and external energy of interaction, optimality and perfection of energy-information images, structures and systems of different origin. 
Mathematically, the principles and methods of quantitative valuation of harmony of various energy-information images and systems are also unified.

The methods and techniques of building engineering optimal images and creation of perfect anthropological energy-information images according to the criterion of maximum harmony are isomorphic, identical and unified.

Energy-information images formed according to the maximum harmony criterion should be related to optimal correlation ones.

Optimal correlation engineering energy-information devices and systems have been developed extensively in the second half of the $20^{\text {th }}$ century, primarily, for effective command and control of troops and weapons control.

An especially explosive quantitative and qualitative development of these systems occurred during the intensive arms race between the U.S.S.R. and the U.S.A. Thus, highquality energy-information tactical control systems were in demand as much as nuclear missile weapons. Essentially, the best minds, the elite of civilisation worked for long on the problems of developing and improving nuclear missile weapons and the best tactical control systems.

The best, premium quality systems, were those belonging to optimal control and communication ones. An outstanding role in the scientific substantiation of optimal control and communication systems belongs to American scientists Norbert Wiener [10], the father of cybernetics, and Claude Shannon [9] who developed the theory of information. N. Wiener established the quantitative measure of optimal control. C. Shannon determined the quantitative measure of information and developed on this basis the mathematical theory of communication, and the concepts of building optimal engineering energy-information systems. These luminaries laid the foundations for development of optimal control and communication systems for many ages ahead.

C. Shannon's genius was in that he theoretically, from the scientifically viewpoint, laid the groundwork for the appropriate line of development of control and communication systems using complex multibasis orthogonal signals. These systems demonstrated the best theoretical and practical performance indicators. The information systems highquality drive was reduced to developing the highest energy potential provided by employing the principles of harmony and integrity, and creating a high level of development of harmonised engineering systems.

Harmonised engineering energy-information systems are capable, provided complex signals with a high basis (up to infinity) are used, of ensuring superior information indicators - validity and an information transmission rate with minimal energy consumption per bit of information and minimal radiation power.

The experience of developing energy-information systems in the $20^{\text {th }}$ century proved invaluable both for a deep insight into challenging engineering ideas and a better scientific understanding of entities, structures, and systems - of humans and collectives of people.

The concept of optimality is a key one for building effective energy-information systems. However, the abstract word "optimality" failed to help synthesise optimal devices and systems. Development of optimal devices and systems became a reality only after the criteria of optimality were substantiated scientifically. 
Using isomorphism can help synthesise not only optimal engineering systems, but also perfect bioenergy-information ones. The problem of developing a perfect human can be solved after the criterion of perfection has been substantiated. Substantiating and establishing the criteria of human perfection makes the solution of the problem of developing a perfect Man real.

\section{Key research results}

It has been proved [2-7] that

The Law of Harmony of the CREATOR defines:

- balance, equilibrium, "razor's edge", the "golden mean" between opposite energies "+" and "-", between opposite categories "Yin-Yang", zero mutual correlation between different energy-information images;

defines:

- the balance between two opposite ethical categories "give and take", and between "receive and grant";

- accord, mutual understanding, concession, compromise;

- harmony - morals, harmony-peace between different energy-information images, peace among people.

Peace, harmony-peace - key words for ensuring life in the Universe

defines:

- strict observance of the ethical precept "do no harm"

defines:

-engkratia - restraint, emotional balance, self-possession;

defines:

- tolerance - tolerance to other beliefs and opinions.

\section{The practical implementation of the Law of Harmony of the CREATOR achieves}

the formation of high-quality energy of external interactions between different energyinformation images, the formation between them of outer harmony, harmony-morality, and peace.

\section{The Law of Harmony of GOD defines:}

- unity, fusion, autocorrelation of the real energy-information image with a paragon;

defines:

- the quality of positive energy of internal interactions between a real energyinformation image and a paragon, an ideal, GOD; 


\section{defines:}

- harmony-morality, harmony-love, love of GOD. GOD creates positive "+" energy, energy of supreme quality based on harmony-love among people.

\section{Love, harmony-love - key words for ensuring life in the Universe.}

The practical implementation of the Law of Harmony of GOD

\section{achieves}

the formation of high-quality energy of internal interactions between a real energyinformation image and a paragon, the formation between them of internal harmony, harmony-morality, and love.

In [5], there is a HYMN written with the help of the CREATOR and GOD. It is dedicated to two sacred words - PEACE and LOVE.

The text of the HYMN is presented as three ESSAYS:

- PEACE,

- LOVE,

- HARMONY-PERFECTION.

HYMN - a gift for all people of the Universe. Come to love our HYMN and you will understand and appreciate the Laws of Harmony of the CREATOR and GOD. They will transform your life, and make it lovely and happy.

LOGOS of CHRIST: "Only harmony can make people happy. Stand together and help one another. Your strength is in unity and mutual understanding. Only in this way you will be able to stand up to the forces of evil and bear up hardship." [2]

LOGOS of the LORD GOD: "In standing together, you will be able to progress more easily, support one another on all severe and dangerous legs of the path, and every one of us will experience a lot of them.

Your civilisation has to attain a qualitatively new level of consciousness gradually, but in short time." [2]

Ancient Greeks asserted:

$\mathrm{H} \alpha \rho \chi \eta \circ \lambda \eta \zeta \omega \eta \alpha \pi \circ \tau o \lambda \circ \gamma o \varsigma$ - this means that the basis and primary source of all life is LOGOS [2].

To introduce the Laws of Harmony of the CREATOR and GOD into life, it is required to introduce into life LOGOS - ORTHOGONALITYORTHONORMALITY - the energy of PEACE and LOVE.

\section{Conclusions}

The true challenge of Humanity is to combine the prime achievements of natural sciences with the achievements of theology, and the Laws of Harmony of the CREATOR and GOD.

A human being, who is perfect according to the criterion of maximum harmony, is an integral orthogonally-orthonormalised image possessing supreme moral-ethical qualities, the energy of PEACE and LOVE. 
The CREATOR and GOD proclaim the fundamental right of all people in the Universe - the right to life.

Mathematically it was proved that the biggest obligation and the sacred duty of all intelligent entities is to observe strictly the Laws of Harmony of the CREATOR and GOD.

To remove the program of self-liquidation and self-destruction, it is necessary, in the first place, to change the world outlook.

The research conducted is focused to cognising the methods of developing a new Man, new reasoning, a new world outlook, and establish an ERA of PEACE and LOVE by in-depth mathematical studies into the content of harmony, moral-ethical rules, norms, principles, canons, Great Cosmic Laws of Development, and the Laws of Harmony of the CREATOR and GOD. This is how we perceive the strategy of holistic sustainable development of Man and Humanity in the Aquarius epoch.

\section{References}

1. Fichtenholz G.M. Course of Differential and Integral Calculus. - M.: FIZMATGIZ, 2005. - V. III. - 728 pp. [In Russian]

2. Suvorov N.P. A $\rho \imath \tau \sigma \varsigma \alpha \nu \theta \rho \omega \pi o \varsigma$ - Perfect Man. - M.: E.RA, 2014. - 304 pp. [In Russian]

3. Nikolay Suvorov and Irina Suvorova. Scientific basics of forming human quality and perfection to ensure holistic sustained development. European Journal of Sustainable Development (2015), 4, 1, 149160. Doi: 10.14207/ejsd.2015.v4n1p149. ISSN: 2239-5938.

4. Nikolay Suvorov and Irina Suvorova. The Concept of Holistic and Sustainable Development Based on Harmony. European Journal of Sustainable Development (2015), 4, 2, 227-234. Doi: 10.14207/ejsd.2015.v4n2p227. ISSN: 2239-5938.

5. Nikolay Suvorov and Irina Suvorova. Peace, Love, Harmony and Perfection are the Basic Components of Holistic Sustainable Development of the Nations and Civilisation. European Journal of Sustainable Development (2016), 5, 3, 383-396. Doi: 10.14207/ejsd.2016.v5n3p383. ISSN: 22395938.

6. Nikolay Suvorov and Irina Suvorova. The Switzerland Phenomenon - An Example of Sustainable Development of a Nation. European Journal of Sustainable Development (2017), 6, 3, 61-68. Doi: 10.14207/ejsd.2017.v6n3p61. ISSN: 2239-5938.

7. Nikolay Suvorov and Irina Suvorova. Scientific Substantiation of the Development-Evolution of New Man Founded on High-Quality Interaction Energy Created by Using Harmony, Ethical Canons and Holistic Principles. European Journal of Sustainable Development (2017), 6, 4, 531-537. Doi: 10.14207/ejsd.2017.v6n4p531. ISSN: 2239-5938.

8. Explanatory Dictionary of the Russian Language by V. Dahl. OLMA Media Group Publishers (2010), 576 pp. ISBN:978-5-373-03764-8.

9. Shannon C. Works in the Theory of Information and Cybernetics. - M.: Foreign Literature Publishers, 1963. - 830 pp. [In Russian]

10. Wiener N. Cybernetics: or Control and Communication in the Animal and the Machine. 1948-1961. - $2^{\text {nd }}$ edition. - M.: Nauka Publishers; Main Editorial Board for Publications for Foreign Countries, 1983. - 344 pp. [In Russian] 